\title{
La expresión en las fronteras del lenguaje. Sobre el eterno retorno de Nietzsche*
}

Fecha de entrega: 18 de noviembre de 2019

Fecha de evaluación: 30 de noviembre de 2019

Fecha de aprobación: 1 de diciembre de 2019

\author{
Sergio Quitián Zárate
}

\section{Resumen}

A partir de la interpretación que Giorgio Colli hace de Friedrich Nietzsche y de su propia apuesta teórica, se pretende aquí bosquejar una alternativa filosófica que afronte la devastadora crítica que el pensador alemán inauguró en torno al poder del lenguaje; esto al tomar como base para tal propuesta el concepto de expresión. Con esto, se busca aportar una nueva forma de divisar las fronteras del lenguaje, más allá del mundo de la representación y mucho más cerca de la experiencia inmediata del individuo con el mundo del fenómeno, la apariencia y los modos de nombrar lo que acaece cada vez.

Palabras clave: expresión, lenguaje, fenómeno, apariencia, representación.

* Este trabajo surge como una investigación en el curso de la Maestría en Filosofia de la Universidad de los Andes al revisar las interpretaciones de Friedrich Nietzsche sobre el pensamiento presocrático a raiz de sus aportes filológicos. En esta exploración, la figura de Heráclito y la profundidad del logos que anunciaba, articulada a la carrera teórica del traductor de Nietzsche más representativo, Giogio Colli, nos condujo por diversos caminos que recalaron en la mirada retrospectiva al uso del lenguaje como creador del mundo, a su ambivalencia teorética y a sus implicaciones ontológicas.

Citar como: Quitián Zárate, S. (2020). La expresión en las fronteras del lenguaje. Sobre el eterno retorno de Nietzsche. Cuadernos de Filosofía Latinoamericana, 41(122), 193-204.

DOI: https://doi.org/10.15332/25005375/5533

* Licenciado en Filosofía y Lengua Castellana de la Universidad Santo Tomás; magister en Filosofía de la Universidad de los Andes. Correo electrónico: s.quitian@uniandes.edu.co 


\section{Expression in the Boundaries of Language. Regarding Nietzche's Eternal Return}

\section{Abstract}

Based on Giorgio Colli's theoretical stance and his interpretation of Friedrich Nietzsche, this paper intends to sketch a philosophical alternative that faces the devastating criticism regarding the power of language inaugurated by the German thinker, taking as a basis for such a proposal the concept of expression. With this, we seek to provide a new way of tracing the boundaries of language beyond the world of representation and much closer to the individual's immediate experience of the world of phenomena, appearance and ways of naming what happens moment by moment.

Keywords: expression, language, phenomenon, appearance, representation.

No el mundo como cosa en sí, sino el mundo como representación (como error), es tan rico en significado, profundo, prodigioso, preñado de dicha y de desdicha.

Friedrich Nietzsche, Humano, demasiado humado

Ya es bastante conocida la profanadora crítica nietzscheana a las aventuras lingüísticas del hombre soñador, aquel que, encumbrado en sus portentosos edificios de conceptos, se ha apoderado de los límites y los valores de un mundo débil, repleto de abstracciones. Sobre este viejo desengaño no podemos reposar. Más allá de afirmar que Nietzsche fue un genio de la percepción y consiguió comprender con clarividencia las artimañas metafóricas del intelecto humano, que su talento filosófico sobrepasa la media y ha de ser valorado como un pensador extemporáneo, que no podemos más que alabar sus elucubraciones y aferrarnos a sus intempestivas campañas como fieros discípulos de un legado ya lo bastante público; el trabajo por hacer no puede relegarse a seguir huellas y enfurecer discursos, ya de por sí, iracundos y nostálgicos. 
El camino y el curso de la filosofía ha de desembarazarse de la idolatría de la crítica y de la tendencia exacerbada a fruncir el ceño cual garantes de un escepticismo inmóvil.

Lo de Nietzsche es algo sin precedentes, que cabría también ser considerado como sin consiguientes. Lo que se diga y se siga diciendo en torno a los artificios del lenguaje, a las catedrales de las palabras y al endeble sentido de las alusiones metafóricas, no deja de ser repetición y plagio. Toda reflexión en torno al lenguaje como creador de verdad, a sus discursos, sus manías, sus entramados ideológicos y a las profundas raíces morales en las determinaciones de los significados de las palabras, es asunto de ciencias añejas y neófitos entusiastas de la comprensión filosófica del mundo moderno. Sin embargo, quizá sí exista aún una inédita cuestión que el “maestro” planteó y dejó en suspenso, tal vez esperaba responderla en otro momento o someterla a juicios ulteriores, quizá confiaba su sutil pregunta a las preocupaciones filosóficas de la posteridad: “Es el lenguaje la expresión adecuada de todas las realidades?” (Nietzsche, 2000, p. 4).

Dicho cuestionamiento no vale señalarse como banal ni pueril. El problema de la expresión no es, en modo alguno, un asunto baladí. Si Nietzsche se interroga por la relación existente entre expresión y realidad, su preocupación recala en la eventual consonancia entre las palabras y las $\operatorname{cosas}^{1}$, en la figuración o proporción que cabe entre verdad y naturaleza ${ }^{2}$. Al decir de Nietzsche, el lenguaje apenas se limita al efecto consolador de la designación, allí donde el intelecto, menesteroso de ficción para la paz y la tranquilidad — superada la hostilidad de la existencia-, recrea con palabras relaciones apenas posibles de las cosas con los hombres. Cualquier derivación lingüística funciona como un ladrillo en la construcción de los conceptos, que en sumatoria permiten edificar el laberinto de la verdad. La autocomplacencia parece ser el instinto racional que motiva esa fuerza de la expresión. De ahí que la sugerencia nietzscheana, en torno al móvil antropomórfico del lenguaje y de la ciencia, pueda encontrar su asidero en una reflexión eventual sobre el problema de la expresión como salida y éxodo veritativo, como representación de las insuficiencias y la búsqueda de respuestas infundadas pero útiles. En lo que sigue, se buscará plantear una interpretación preliminar al pensamiento de Nietzsche desde su crítica al lenguaje y desde la perspectiva

1 En este punto no es válido establecer relaciones interpretativas o temáticas entre la expresión usada y el título de la reconocida obra de Michel Foucault, Las palabras y las cosas (2008).

2 A su vez, esta expresión sí tiene una marcada influencia heracliteana que será esbozada hacia el final de este ensayo. 
del concepto de expresión, que funciona como retorno hacia una posible relación con la inmediatez - de alguna manera más cercana, consciente y prudente que aquella a la que el lenguaje metafórico e ilusorio nos ha tenido habituados a aceptar y asumir.

\section{Las contrariedades del lenguaje}

Para el pensador del martillo, el poder del lenguaje radica en su fuerza figurativa. La posibilidad de diseñar alicientes para contrarrestar la existencia gris y precaria está dada en el vehículo racional de la palabra. Ahora bien, el espíritu movilizador de dicha tendencia de salvaguarda es representado por Nietzsche (2009) en la figura del dios griego Apolo. El dios del conocimiento, de la adivinanza y de la ensoñación, es el fiador que conspira contra los malestares del mundo para adornar con arte, belleza y luz las tinieblas y las horrendas condiciones de la vida en su estado bruto. La fuerza transfiguradora que auspicia Apolo permite al hombre ser salvado por la palabra, descansar en un foco de apariencia lenitiva que lo aleje del terror y del dolor. Con todo, el influjo de aquella necesidad metafísica de consuelo, de la que habla Nietzsche, crea un velo de satisfacción que genera con las palabras el imperio de una verdad necesaria. El hombre precisa de los conceptos, las significaciones bellas y los artificios del lenguaje para sobrellevar su existencia, para tornarla amena y digna de ser vivida. En este sentido, el conocimiento deja de cifrarse en técnicas para descubrir la naturaleza, pues esta no ofrece más que desesperanza y parece sólo sembrar miedo, y se configura mejor como un modo - demasiado humano- de velar la naturaleza y crear sobre su enigma un nuevo campo de confort lingüístico. El encanto y la conformidad son las bases sobre las que se establece esa fuerza de encubrimiento que sería el conocimiento. El hombre racional se hace como artífice creador y genio del consuelo en soñador; "nuestro ser más íntimo, el substrato común de todos nosotros, experimenta el sueño en sí con profundo placer y alegre necesidad" (Nietzsche, 2009, p. 43).

De las artimañas del sueño y las palabras, la música y sus alabanzas, no hay duda de que funcionan como redención. El hombre crea entonces la dulce necesidad de ser un virtuoso del lenguaje para adornar e iluminar cada vez mejor el desolador panorama de la naturaleza:

Apolo nos sale de nuevo al encuentro como la divinización del principium individuationis, sólo en el cual se hace realidad la meta eternamente alcanzada de lo Uno primordial, su redención mediante la apariencia: él nos muestra 
con gestos sublimes cómo es necesario el mundo entero del tormento, para que ese mundo empuje al individuo a engendrar la visión redentora, y cómo luego el individuo, inmerso en la contemplación de ésta, se halla sentado tranquilamente, en medio del mar, en su barca oscilante. (Nietzsche, 2009, p. 60)

La contemplación de la esencia de las cosas, el descubrimiento de su sustrato último, no son intereses reales y efectivos del hombre racional. Para Nietzsche (2009), el genio helénico logró comprender que la fuerza del conocimiento se hallaba en la capacidad de la apariencia para formar un mundo posible y locuaz, una aventura de arquitectos que con palabras, notas musicales y valores supremos pudieron adueñarse de una realidad que no era propia.

Ahora bien, el llamado de creación de ese momento, a saber principium individuationis, para Nietzsche (2009), dejó su misión figurativa y sedativa cuando se estableció como imagen de un orden a tal punto estructurado que impidió la multiplicidad y el gozo, y se estableció como única posibilidad, como verdad eterna. El hombre entonces "olvida, por lo tanto, que las metáforas intuitivas originales no son más que metáforas y las toma por las cosas mismas" (Nietzsche, 2000, p. 8), este tiende a soñar más que a descubrir y cada que se suma un siglo se hunde más en la ley de lo onírico; se aferra de tal forma a los conceptos que ha logrado abolir lo que antes se consideraría como oculto.

El efecto traumático del llamado principium individuationis viene acompañado del distanciamiento y posterior aislamiento del hombre racional, que se considera a sí mismo dueño y señor de un mundo nuevo. El velo reconfortante de la apariencia insta al hombre por la fuerza apolínea a la creación. Ahora bien, el exacerbado cultivo del entendimiento trasgrede los límites que enmarca la búsqueda de una existencia menos pesarosa y llega a los confines de abstracciones lingüísticas peligrosas, para la vida misma. Al decir de Nietzsche (2009), el principium individuationis garantiza al hombre la posibilidad de sustraerse a la totalidad, y esto remite al vacío que encierran sus consecuencias, pues la fuerza redentora de Apolo no precisaba un retraimiento sin más. La intención primigenia era, más bien, volver por medio del arte al Uno primordial perdido: "Como fenómeno estético, la existencia nos sigue siendo todavía soportable, gracias al arte se nos regalan los ojos y las manos y, sobre todo, la buena conciencia para poder hacer de nosotros mismos un fenómeno semejante" (Nietzsche, 2001, p. 199). Pero como la tendencia conceptual no se encasilló en meros paliativos 
y soñó tanto que no pudo más que enamorarse de sí misma, el principium individuationis derivó en logos corrupto, en falsedad anquilosada, en construtos etéreos de axiomas, evangelios y ortodoxias.

Las consecuencias son desoladoras. El arte ha sido relegado de su función metafísica de consuelo primordial, y sobre este se han erigido la moral, la religión y la ciencia. Toda posible explicación del mundo parte de un distanciamiento de la naturaleza y un ensimismamiento en el concepto; cualquier respuesta válida ha de configurarse como miembro de un canon de verdades que el lenguaje ha dotado de absoluta validez: "Uno sólo nunca tiene razón: pero ya con dos comienza la verdad. Uno solo no puede demostrar nada: pero con dos no cabe ya refutar" (Nietzsche, 2001, p. 262). Las ilusiones se vuelven principios y los adornos metafóricos dejan de ser ficción ante los ojos del artista para convertirse en substancia del mundo para la consciencia del hombre moderno. Asistimos a la antropomorfización de la realidad: "Nosotros operamos con cosas que simplemente no existen: líneas, superficies, cuerpos, átomos, tiempos y espacios divisibles - ¡Cómo sería posible la explicación, si antes nosotros todo lo reducimos a una imagen, a una imagen nuestra!” (Nietzsche, 2001, p. 207) ${ }^{3}$.

El poder legislativo del logos omite la experiencia individual y generaliza, en orden a la representación más racional, el mundo en el que se debe vivir, aquél que es digno de ser pensado. Y aunque la precisión sobre este punto en Nietzsche es clara, que el lenguaje apenas da cuenta de la designación de las relaciones de los hombres con las cosas, las derivaciones conceptuales son mucho más potentes y ficticias; situación que da cauce a un sinnúmero de realidades confinadas a la mentira y la ilusión inconsciente:

En ese instante el hombre pone sus actos como ser racional bajo el dominio de las abstracciones: ya no soporta ser arrastrado por las impresiones repentinas, por las intuiciones y, ante todo, generaliza todas esas impresiones en conceptos más descoloridos, más fríos, para uncirlos al carro de su vida y de su acción. (Nietzsche, 2000, p. 6)

3 En contra de las concepciones "naturalizadoras" del lenguaje, que invocan afinidad e incluso correspondencia entre las palabras y las cosas, cabe recordar la tan citada discusión de Cratilo y Hermógenes reconstruida por Platón (2018), que aunque no puntualice radicalmente una postura en la figura de este, si evidencia las dificultades al considerar que las palabras son representaciones fidedignas de los objetos o que existen relaciones de identificación fonética que se puedan desplazar al campo semántico. 
Hasta aquí la crítica nietzscheana funciona como manifiesto, por amor a la protesta, en virtud de un discurso crítico sobre su misma enunciación. Cabría considerar su intempestiva campaña como un logro significativo. Ahora bien, ¿qué sentido tiene adelantar una presunta crítica al lenguaje por medio de un examen de las palabras, de su rol veritativo y de sus consecuentes implicaciones de ilusión y engaño, y usar como instrumento y arma aquellas mismas palabras a las que se presta recelo? Toda crítica al lenguaje es conducida por su propio enemigo hacia un callejón sin salida. Nos hemos distanciado de las cosas, la representación sólo versa sobre sí mismos: el mundo real nos es ajeno, pues sólo conocemos este que nos determina, nos descubre, aquél que creamos y nos crea:

[...] lo que ahora llamamos el mundo es el resultado de una multitud de errores y fantasías que fueron paulatinamente naciendo en la evolución global de los seres orgánicos, concrescieron y ahora heredamos nosotros como tesoro acumulado de todo el pasado; como tesoro, pues en él estriba el valor de nuestra humanidad. (Nietzsche, 2007, p. 52)

De lo anterior se sigue que, el poder lingüístico redentor, creador y transfigurador responde a una necesidad biológica exacerbada que nos enfiló hacia el autoengaño y a la soberbia racional, y consiguió que el encumbrado logos - que podemos relacionar históricamente con la "diosa razón” posrevolución francesa- diseñara artificiosamente realidades adyacentes a nuestra propia naturaleza para satisfacer nuestros deseos de poder, definir un lugar especial en el cosmos para nosotros los dadores de verdad, confiar en símbolos y modelos ante el advenimiento de la muerte; en suma, tomar como criterio la utilidad para que el lenguaje engalane y subvierta la existencia inmediata.

\section{Logos espurio}

El logos dador de verdad desencadenó un flujo de meditaciones y enajenamientos tales que pasó de ser herramienta para el enfrentamiento con la premura y la necesidad a un artilugio redentor en pos de la utilidad. El lenguaje y sus vástagos conceptos pasaron de medios a fines en sí mismos. Presenciamos el nacimiento de la ciencia como respuesta. Ante la progresiva sustancialización del lenguaje, la realidad se convirtió en psicología:

La importancia del lenguaje para el desarrollo de la cultura radica en el hecho de que en él el hombre puso un mundo propio junto al otro, un lugar que 
consideraba tan firme como para a partir de ahí levantar sobre sus goznes el resto del mundo y adueñarse del mismo. Como durante largos lapsos de tiempo el hombre ha creído en los conceptos y nombres de las cosas como aeternas veritates, ha hecho suyo ese orgullo con que se elevaba por encima del animal: suponía tener efectivamente en el lenguaje el conocimiento del mundo. (Nietzsche, 2007, p. 47)

El diagnóstico de una serpiente que arremete contra su propia cola sirve de ilustración para la tendencia autoaniquilante del logos, sea este tomado como razón, discurso o lenguaje; en cualquier caso, su fuerza creativa se filtra por la parodia de novedad y falsedad ${ }^{4}$. El curso de su declive lo marca el desplazamiento en el punto de iniciativa: dotar de belleza al mundo ya no es lo más importante, sino más bien crear mundos bellos. Sin embargo, la determinación del vicio lógico parte de sus mismas carencias, pues, al decir de Giorgio Colli (2004) —el pensador que en este punto toma la bandera y la palabra-, todo lo que tenemos por realidad parece no ser otra cosa que pura representación ${ }^{5}$. El poder del lenguaje surge de la misiva conceptual y predicativa que garantizan las categorías, aquellas que pueden definir y caracterizar al Ser. Ahora bien, siendo estrictos, la posibilidad de "lo dicho" sobre un objeto, sea cual fuere, parte de lo que Nietzsche ya había identificado: la relación que se establece entre los hombres y las cosas (Nietzsche, 2000). De tal modo, lo que hemos de llegar a predicar de la realidad es el resultado de una parcial designación de conexiones provisionales entre sujetos y objetos. Las palabras no dicen las cosas, sino más bien las cosas son representadas por las palabras y creadas en formas categoriales que buscan desentrañar del pasado, del contacto primordial de la experiencia, aquél entramado de contenidos y datos informes. Los nombres son productos de una búsqueda de utilidad, pues en la medida en que los objetos funcionen dentro del constructo de la verdad, cabe considerarlos válidos y absolutos. El criterio de validez se legitima en la representación de sustancias que sirven de recuerdo de la inmediatez. La barrera de la apariencia nos aleja del contacto primigenio, para lo cual, aquello que nos es dado sólo "es" en tanto empieza a "ser" cuando se predica su sustancialidad. El concepto de sustancia es, a su vez, vacío, pues lo que consigue es alimentar las representaciones de una relación perdida en el tiempo

4 Sobre este punto cabe recordar la sugerente interpretación que realizan M. Horkheimer y T. Adorno en su celebérrima obra Dialéctica de la llustración (2007) de este curso de autoaniquilación de la ratio.

5 Y aunque puede establecerse un guiño de relación con Kant y sobre todo con Schopenhauer, la crítica de Colli dista bastante de las concepciones epistemológicas de la Modernidad. 
sobre cosas nombradas sin realidad ulterior: en primer lugar, de un "algo" llamado sujeto, fugaz, imposible de asir ni de concebir si no es como un objeto de otro sujeto; $y$, en segundo lugar, un otro "algo" que parece ser nuestro destino, sin ser diferente a un nombre alusivo y metafórico.

La representación como un volver a traer a la consciencia se constituye como la suprema esencia de las cosas y la función última del logos:

Después de Aristóteles la filosofía no se ha preocupado lo suficiente por indagar qué queremos expresar cuando decimos "ser"; se ha partido más bien de la palabra "ser" y se le han dado uno tras otro los más variados contenidos y significados. Así el lenguaje se convirtió en creador de filosofía, cuando su naturaleza es solamente la de un trámite dinámico que debe conservar, purificar, ordenar y articular, pero no será nunca un arché. La fantasía prelingüística es la matriz de la filosofía. (Colli, 2004, p.104)

Parece ser que sólo los sabios griegos, al decir de Colli (2008), comprendieron el problema del conocimiento desde una perspectiva no "perspectivística"; es decir, no limitaron la posibilidad del objeto en términos de conceptos, sujeto y sustancia - de categorías y lógica-, sino que asumieron la relación con la inmediatez como un continuo juego de descubrimientos y alusiones, tal y como Nietzsche (2009) reconoce en el genio helénico por medio del arte, y como hemos comprendido que ha quedado vedado bajo el imperio de la apariencia.

¿Cómo salir entonces de los laberintos que los cercos de las palabras han sembrado con el ímpetu racional del logos espurio?, ¿hacia dónde conduce la utilidad del lenguaje en los senderos de la creación paliativa? Una posible "terapéutica del lenguaje" que razone sobre los correctos usos de las palabras, los límites de los nombres y maneje con cautela el poder de los conceptos, no dejaría de ofrecer visos sobre la tendencia científica, moral y religiosa que adoptan las metáforas, antaño necesarias para resarcir la carencia de nuestra propia naturaleza.

\section{Una mirada lingüística al margen del logos: la expresión}

Previa a toda representación se haya la inmediatez. El contacto directo y primigenio con la naturaleza, empero, carece de toda determinación posible en términos 
predicativos, pues lo que nombramos con adjetivos o localizamos en lugares y tiempos solo hace parte de un curso representativo. El origen no abstracto del contacto no se encuentra determinado por ningún tipo de condición, para lo cual las atribuciones sólo sirven de aliciente al olvido marginal de la visión primigenia de la physis. Conocer bajo la forma del recuerdo da lugar a la abstracción como consecuencia memorística de la representación, con lo cual la nostalgia de la fugacidad recrea en el intelecto categorías y juicios que completan la dinámica del contacto. Un “algo" que ha sido tocado por la naturaleza sin determinación alguna buscará completar el círculo del contacto intentando dar cuenta de su experiencia, para lo cual renueva su sentir con predicados definitorios, representaciones y conceptos que le permitan acceder al misterio del que fue objeto. Así es que se vuelve el hombre un ser racional, responsable de hallar verdad y sentido en (a) la naturaleza, aquella que no conoce, no crea, y por ende re-conoce y re-crea en el ejercicio de su capacidad intelectiva. Cada paso hacia el conocimiento es un acercamiento al mismo sujeto y un distanciamiento de la naturaleza. El lenguaje deslinda el contacto pues apenas rememora la pérdida de la inmediatez. De ahí que la alternativa del descubrimiento se encuentre dada, evidentemente, por la fuerza luminosa del faro apolíneo.

Para Colli (2004), la posibilidad de sustraerse a las cadenas de la representación y acercarse de alguna manera a la naturaleza oculta se encuentra en el reintegro del camino discursivo a los flujos expresivos prelingüísticos. De antemano se da por sobreentendido que la naturaleza nos es abstrusa, lejana, oculta. Cabe recordar el fragmento

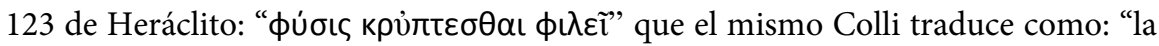
naturaleza ama esconderse" (Colli, 2008). El hombre no puede comprender el enigma de la naturaleza, su esencia es el velo que ella misma pone sobre sí y que se acentúa con las incapacidades humanas para su descubrimiento. No es posible superar la brecha que separa al hombre de la naturaleza auténtica, con lo cual apenas logra adjetivar sustancialidad y dotar de atributos propios eso oculto que le preocupa. Sin embargo, previo a toda representación que funciona como respuesta al miedo y al malestar del no-saber, Colli reconoce la presencia de un movimiento interno en el hombre que data con más cercanía al contacto con la inmediatez que la predicación misma, a saber, la expresión. Para Colli (2004), la expresión encierra aún el paso de una forma a otra que, sin embargo, guarda algo de la primera en tanto manifiesta el carácter oculto de la naturaleza que busca ser expresado. La expresión alude, recuerda, trae consigo el momento extraño en que "algo" en el pasado aconteció y sirvió de aliciente a la experiencia. No es vano que la sabiduría griega se expresara enigmáticamente - piénsese 
en el Oráculo o en las sentencias oscuras de los presocráticos-, el hecho de salir de sí para poner de manifiesto el carácter oculto de la naturaleza por medio de la misma opacidad de las palabras mantiene un nexo mucho más cercano con la inmediatez perdida en los pensadores helénicos:

En el abismo de la inmediatez hay una resistencia, un obstáculo, una contracción (hablando simbólicamente), y la expresión lleva todo esto consigo. La carencia que está en el contacto es algo insuperable: la expresión refuerza esta insuficiencia, aun cuando su significado, en la manifestación de esta resistencia, sería huir de ella, superarla. Pierde la inmediatez, pero inventa, completa aquello que le falta al contacto: la totalidad. Si en lo profundo pudiera cambiar algo, los contactos se confundirían en una totalidad inextensa, extra-representativa. En cambio se alcanza una totalidad extensiva sólo si se abandona la inmediatez, y es casi como una reparación por aquel abandono. (Colli, 2004, p. 77)

Si bien Nietzsche considera que no somos buenos vecinos de las cosas próximas (Nietzsche, 2007), pues no mantenemos relación directa con aquello que nos es cercano e inmediato, la interpretación de Colli sobre la sabiduría griega y el logos espurio parece que dibuja de alguna manera el posible camino hacia una buena vecindad: comprender la expresión apenas como una hipótesis prelingüística ${ }^{6}$ del contacto con la inmediatez, donde se admite la carencia de su enunciación y se conmueve con la tendencia natural a la adquisición y complementación sobre el suelo de la apariencia. No podemos dejar de representar y ser representados, pero la aclaración de nuestras limitaciones y el sigilo de la expresión en su dinámica de cercanía y recuerdo pueden hacer enmudecer a un nostálgico poeta o a un vanagloriado filósofo. No decimos lo que son las cosas, apenas somos lo que decimos. Ahondar en el significado de lo que representa la inmediatez o la expresión sería anteceder una figuración literaria anterior al momento mismo del acontecimiento, con lo cual, toda la crítica acá mostrada caería en nuevas vacilaciones. La expresión es una hipótesis que prescribe su privación y aun así nos remite a una salida hacia el exterior autocreado. Reparamos el dolor del abandono cuando las palabras se agotan y no sabemos qué decir sobre aquello que

6 Entendemos por prelingüistico todo aquello que entra en el dominio de la expresión dentro de la dialéctica de contacto con el exterior y reconocimiento intelectual bajo la figuración directa con símbolos o estrategias emotivas; es decir, sin la ejecución de la palabra como forma paradigmática de decir el mundo, y al asumir posturas más contemplativas o receptivas sin conducir necesariamente a la formulación de juicios. 
hemos perdido, cuando no sabemos responder a la cuestión de si el lenguaje es, en efecto, la expresión adecuada de todas las realidades.

\section{Referencias}

Colli, G. (2000a). Después de Nietzsche. Barcelona: Anagrama.

Colli, G. (2000b). Enciclopedia de los maestros. Barcelona: Seix Barral.

Colli, G. (2004). Filosofía de la expresión. Madrid: Siruela.

Colli, G. (2008). La naturaleza ama esconderse. Madrid: Siruela.

Colli, G. (2010). La sabiduría griega III: Heráclito. Madrid: Trotta.

Deleuze, G. (2008). Nietzsche y la filosofía. Barcelona: Anagrama.

Ferro, J. (1974). Nietzsche y el retorno a la metáfora. Barranquilla: Uninorte.

Nietzsche, F. (1974). El libro del filósofo. Madrid: Taurus.

Nietzsche, F. (2000). Sobre verdad y mentira en sentido extramoral. Recuperado de: http://www.lacavernadeplaton.com/articulosbis/verdadymentira.pdf

Nietzsche, F. (2001). La ciencia jovial (la gaya scienza). Madrid: Biblioteca Nueva.

Nietzsche, F. (2003). Los filósofos preplatónicos. Madrid: Trotta.

Nietzsche, F. (2007). Humano, demasiado humano. Un libro para espíritus libres. Madrid: Akal.

Nietzsche, F. (2009). El nacimiento de la tragedia. Madrid: Alianza.

Nietzsche, F. (2011). Filósofos sobrehumanos. Madrid: Siruela.

Platón. (2018). Cratilo. En Platón II (pp. 339-461). Madrid: Gredos. 